\title{
All we know about COVID-19 in pregnancy: from perinatal to ethical and psychological perspective
}

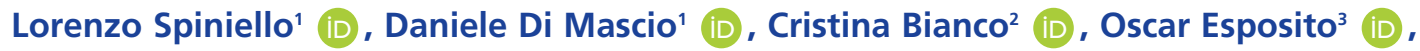 \\ llaria Giangiordano ${ }^{4}$ (DD, Ludovico Muzii' ${ }^{1}$, Antonella Giancotti ${ }^{1}$ (DD), \\ Roberto Brunelli' (ID), Gabriele Saccone ${ }^{5}$ \\ ${ }^{1}$ Department of Maternal and Child Health and Urological Sciences, Sapienza University of Rome, Rome, Italy \\ ${ }^{2}$ Department of Law, University of Naples Federico II, Naples, Italy \\ ${ }^{3}$ Department of Obstetrics and Gynecology, Santobono-Pausilipon Hospital, Naples, Italy \\ ${ }^{4}$ Department of Child and Adolescent Neuropsychiatry, Local Health Unit of Avezzano-Sulmona-L'Aquila, Sulmona, Italy \\ ${ }^{5}$ Naples Department of Neuroscience, Reproductive Sciences and Dentistry, School of Medicine, University of Naples Federico II, Naples, Italy
}

\begin{abstract}
The Novel Coronavirus (SARS-CoV-2), also known as Wuhan coronavirus, causes the $2019-\mathrm{nCoV}$ acute respiratory disease or COVID-19. While coronavirus infection is a common and usually self-limiting infection, in a specific population like pregnant women, complications of the disease appear to be more relevant, and pregnant women are particularly susceptible to morbidity and mortality, especially in case of high pathogenicity virus. Most common complications associated with COVID-19 in pregnancy include preterm birth, cesarean delivery, and perinatal deaths. The risk of vertical transmission seems to be negligible.
\end{abstract}

Keywords: COVID-19, pregnancy, maternal mortality, perinatal outcomes.

\section{Introduction}

In December 2019, a novel Coronavirus (COV), labelled as Severe Acute Respiratory Syndrome Coronavirus-2 (SARS-CoV-2), caused a global pandemic identified as COVID-19 that originated in Wuhan, Hubei (China), and then began spreading rapidly across China and all around the world. COVID-19 infection has rapidly spread in many countries as a global pandemic, with the number of affected cases dramatically increasing world-
Özet: Gebelikte COVID-19 hakkında tüm bildiklerimiz: Perinatal perspektiften etik ve psikolojik perspektife

Wuhan koronavirüsü olarak da bilinen Yeni Tip Koronavirüs (SARS-CoV-2), 2019-nCoV akut solunum hastalığına veya COVID-19'a sebep olmaktadır. Koronavirüs enfeksiyonu, gebe kadınlar gibi belirli bir popülasyonda yaygın ve genellikle kendini k1sıtlayıcı bir enfeksiyon iken, hastalığın komplikasyonları daha ön planda görünmektedir. Yüksek patojeniteli virüs durumunda gebeler morbidite ve mortalite yönünden özellikle risk altındadır. Gebelerde COVID-19 ile ilişkilendirilen en yaygın komplikasyonlar arasında preterm doğum, sezaryen doğum ve perinatal ölümler yer almaktadır. Dikey bulaşma riski göz ardı edilebilir seviyededir.

Anahtar sözcükler: COVID-19, gebelik, maternal mortalite, perinatal sonuçlar.

wide on a daily basis. At the moment of this writing, there are more than 5,000,000 test-confirmed and about 335,000 deaths in the world. ${ }^{[1]}$

The virus is transmitted mainly via respiratory droplets and/or contact and typically presents with fever, cough and dyspnea. Despite the relatively low mortality, one of the main problems related to COVID-19 infection is the development of an acute respiratory distress syndrome, often requiring invasive ventilation.

Correspondence: Gabriele Saccone, MD. Naples Department of Neuroscience, Reproductive Sciences and Dentistry, School of Medicine, University of Naples Federico II, Naples, Italy. e-mail: saccone.1990@gmail.com / Received: May 28, 2020; Accepted: June 9, 2020

Please cite this article as: Spiniello L, Di Mascio D, Bianco C, Esposito O, Giangiordano I, Muzii L, Giancotti A, Brunelli R, Saccone G. All we know about COVID-19 in pregnancy: from perinatal to ethical and psychological perspective. Perinatal Journal 2020;28(2):120-126. doi:10.2399/prn.20.0282008

ORCID ID: L. Spiniello 0000-0002-1153-0600; D. Di Mascio 0000-0002-6560-3393; C. Bianco 0000-0002-1143-8783; 
The homology between the SARS-CoV-2 and SARS-CoV-1 genomes has been reported to be about $82 \%,{ }^{[2]}$ and while the overall mortality rate appears to be lower than previous epidemics caused by two other Coronaviruses, also known as $\mathrm{SARS}^{[3]}$ and MERS, ${ }^{[4]}$ a higher rate of patients require admission to the intensive care unit (ICU). ${ }^{[5]}$

The main concern when focusing on COVID-19 and pregnancy is that physiological adaptations occurring during pregnancy might predispose women to a more severe respiratory disease, thus leading to higher rates of maternal and fetal complications. Due the limited information currently available, there are still several outstanding issues that need to be highlighted to guide the antenatal counselling and management of women with COVID-19 during pregnancy.

The aim of this study is to review what is known so far about COVID-19 infection during pregnancy.

\section{Diagnosis}

COVID-19 is diagnosed on the basis of guidance of World Health Organization (WHO) ${ }^{[6]}$ A confirmed case of COVID-19 is defined as a positive result on reversetranscriptase-polymerase-chain-reaction (RT-PCR) assay of nasal and/or pharyngeal swab specimens. ${ }^{[7]}$ The rate of asymptomatic pregnant women tested positive to COVID-19 at RT-PCR nasal and pharyngeal swab ranges from about $25 \%$ in referral centers where suspected women are evaluated due to symptoms or exposure and then consequently tested for COVID-19, up to $88 \%$ in cohort of women receiving universal screening for SARS-CoV-2. ${ }^{[7]}$

Antibody response generally needs several days to develop. In a study of 173 patients with COVID-19, ${ }^{[8]}$ the median time from symptom onset to antibody response was 12 days for IgM and 14 days for IgG. In the first week since symptom onset, less than 40 percent had detectable antibodies; after 15 days, $\operatorname{IgM}$ and $\mathrm{IgG}$ were detectable in $94 \%$ and $80 \%$, respectively.

Several serological blood tests have reported, but the diagnostic accuracy of blood antibodies is still unclear. The three most common methods are IgM and IgG title measured by either chemiluminescence immunoassay analysis or enzyme-linked immunosorbent assay $(\mathrm{ELISA})^{[8]}$ and a rapid IgM-IgG combined antibody test. ${ }^{[9]}$ Chemiluminescence has a higher detection rate compared to ELISA in detecting COVID-19, with a sensitivity of IgM and IgG of $48.1 \%$ and $88.9 \%$, and a specificity of $100 \%$ and $90.9 \%$, respectively.

The rapid combined antibody test is a simple test that can simultaneously detect IgM and IgG antibodies against SARS-CoV-2 virus in human blood within 15 minutes. The overall testing sensitivity is $88.66 \%$ and specificity is $90.63 \% .^{[10]}$

\section{Clinical Features and Maternal Course of COVID-19 in Pregnant Women}

There is still a limited evidence about the clinical course of COVID-19 in pregnant women. Generally, there is a particularly high risk for pregnant women because they are in a special state of immune suppression and they have physiological adaptations occurring during pregnancy, including increase in tidal volume, diaphragm elevation, increased oxygen consumption, reduced buffering capacity to acidosis and decreased functional residual capacity, that make them intolerant to hypoxia and might predispose pregnant women to a more severe course of pneumonia, that is one of the main concern when managing respiratory disorders during pregnancy. ${ }^{[1]}$ In prior pandemics such as SARS and H1N1, pregnant women were indeed more susceptible to severe illness and had greater mortality than general population. ${ }^{[12]}$ Moreover, COVID-19 may predispose the general population to a thrombotic condition, mostly due to inflammation, platelet activation, endothelial dysfunction, and stasis and this hypercoagulability state might intuitively assume an important role in pregnancy due to its inherent prothrombotic state. ${ }^{[5,6]}$ However, current literature has not elucidated yet the strength of this association in pregnant women affected by COVID-19.

According to the National Institute of Health, ${ }^{[13]}$ the severity of COVID-19 can be classified as: (i) asymptomatic (positive test, no symptoms), (ii) mild (any signs and symptoms without shortness of breath, dyspnea, or abnormal chest imaging), (iii) moderate (lower respiratory disease by clinical assessment or imaging and a saturation of oxygen $>93 \%$ on room air at sea level), (iv) severe (respiratory frequency $>30$ breaths per minute, a saturation of oxygen $\leq 93 \%$ on room air at sea level, ratio of arterial partial pressure of oxygen to fraction of inspired oxygen $<300$, or lung infiltrates $>50 \%$ ), (v) critical (respi- 
ratory failure, septic shock, and/or multiple organ dysfunction).

Conversely, another classification adopted at the beginning of the pandemic divided COVID-19 clinical course into three stages of disease (the so called Wu's criteria): (i) mild (no or mild symptoms), (ii) severe (tachypnea, hypoxia, or $>50 \%$ lung involvement on imaging), (iii) critical (respiratory failure, shock, multiorgan dysfunction). Most of these patients had mild disease and only $1.3 \%$ were critically ill. ${ }^{[14]}$

To date, universal screening for SARS-CoV-2 is performed in almost every institution at admission. There are no specific clinical features that can distinguish COVID-19 from other viral respiratory infections, neither in pregnancy nor in non-pregnant women and currently there.

Fever, cough and dyspnea are the most frequent symptoms of COVID-19 during pregnancy, but also upper respiratory tract symptoms, myalgias, diarrhea, and smell or taste disorders are quite common, as well as in the general population. Pneumonia is the most frequent serious manifestation of infection, mostly characterized by bilateral infiltrates on chest imaging. ${ }^{[5,15]}$ Laboratory findings usually involve lymphopenia, thrombocytopenia, and abnormal liver enzymes.

When considering severe sequelae of maternal infection, the actual rate of pregnant women admitted to intensive care unit (ICU) ranges from $3 \%$ to $5 \%$, with $<2 \%$ requiring mechanical ventilation. ${ }^{[16]}$

Of note, the incidence of adverse events caused by COVID-19 infection during pregnancy appears to be lower than what previously reported for MERS and SARS infections also in terms of maternal mortality: while the mortality rate in pregnant women affected by SARS and MERS ranged from $25 \%$ to $30 \%{ }^{[3,4]}$ the actual rate of maternal mortality associated with COVID-19 is very low. ${ }^{[16]}$

The largest multicenter study (the WAPM study) ${ }^{[16]}$ published in this topic and including 388 pregnant women from 73 different hospitals in 22 countries in Europe, Asia, America and Oceania, showed that in pregnancies complicated by COVID-19 infection, the risk of maternal mortality was $0.8 \%$. Only few other cases published so far reported the occurrence maternal deaths in women generally healthy before the infection.

\section{Obstetrical and Perinatal Outcomes}

One of the first metanalyses published ${ }^{[17]}$ included 19 studies and 79 pregnant women and aimed to explore pregnancy and perinatal outcomes of Coronavirus spectrum infections (defined as either SARS, MERS or COVID-19) occurring during pregnancy. Authors found that hospitalized mothers infected with COVID-19 infection were at higher risk of preterm birth, preeclampsia, cesarean delivery, and perinatal death.

Since then, many other reviews analyzing the association between COVID-19 and obstetrical and perinatal outcomes in larger populations have been published, and results are pretty concordant with these data.

Few data are available for the outcomes of pregnancy when the infection is acquired early in pregnancy. However, the rate of spontaneous miscarriage does not seem to be increased.

Preterm birth (PTB) is one of most frequent complications occurring in pregnancies affected by COVID-19 with an incidence ranging from $15-25 \%$; of note, the majority of the studies does not specify whether PTB was spontaneous or iatrogenic, and it is entirely possible that a considerable part of PTB should be attributed solely to the infection, mostly at the beginning of the pandemic. ${ }^{[17]}$

Furthermore, the incidence of other pregnancy complications, such as preeclampsia, IUGR, SGA and fetal distress was low in the majority of the studies published so far. Certainly, the main concern when managing pregnant women affected by COVID-19 is the risk of adverse perinatal outcomes, and in particular perinatal deaths.

The WAPM study ${ }^{[16]}$ reported that the rate of perinatal mortality was $4.2 \%$, with stillbirth occurring in $2.7 \%(6 / 265)$ and neonatal death in $2.0 \%(5 / 250)$ of cases. These data are higher than what previously reported in other reviews, with both stillbirth and neonatal death occurring in less than $1 \%$ of cases, and the WAPM study authors acknowledge that, although large, the incidence of the adverse perinatal outcome in the overall population is low, thus making the sample size potentially underpowered to drawn any convincing evidence.

When exploring maternal and pregnancy characteristics, authors found that early gestational age at infection, maternal ventilatory supports including either need 
for oxygen or CPAP, and low birthweight were the main determinants of adverse perinatal outcomes in fetuses with maternal COVID-19 infection.

Finally, all the studies published so far are concordant about the negligible risk of vertical transmission. Vertical transmission of infection usually occurs during intrauterine life via the placenta, or during delivery via ingestion or aspiration of cervico-vaginal secretions, and in the post-partum period through breastfeeding. ${ }^{[18]}$ The risk of ingestion or aspiration of cervico-vaginal secretions or contact with perineal infected tissue is higher with vaginal delivery. Mother-to-child transmission is one of the main concerns in any case of maternal infection.

No case of clinical evidence of vertical transmission has been reported in a systematic review including 435 newborns from China, United States and Italy. ${ }^{[16]}$ In the WAPM study, ${ }^{[16]}$ only one out of 250 newborns had suspected vertical transmission (vertical transmission rate $0.4 \%)$. Amniotic fluid was not tested, and specimens from placenta were not obtained, and the newborn was asymptomatic, with a negative RT-PCR test after 14 days of life, thus leading the authors to question whether the infection occurred in utero or immediately prior or after birth.

Evidence for vertical transmission based on elevated IgM antibody values in blood drawn from the neonates following birth has been reported in two small reports, ${ }^{[17]}$ with no positive RT-PCR, and therefore no clear virologic evidence for congenital infection.

Recently, SARS-CoV-2 RNA on the fetal side of the placenta has been described in two mothers infected with COVID-19 and with neonates also positive for the virus at birth, thus revealing the concrete possibility of a mother-to-child transmission. ${ }^{[19]}$

The lack of data during first and second trimester allow neither to evaluate whether the infection acquired early in pregnancy is associated with a higher risk of vertical transmission, nor to ascertain whether invasive prenatal diagnosis like amniocentesis, might determinate if fetus is infected.

\section{Mode of Delivery}

The rate of cesarean delivery in women affected by COVID-19 has been described to be very high, both in systematic reviews and cohort studies, ranging from 50 to $85 \% \cdot{ }^{[20]}$ However, indications for the majority of these deliveries were not available, and it is likely that many cesarean sections have been performed for COVID-19 infection alone.

Based on the limited information from the literature, COVID-19 cannot be considered as an indication for delivery and the timing and mode of delivery should be individualized according to maternal clinical conditions or obstetric factors (and not COVID-19 status alone). The decision should involve a multidisciplinary team including maternal fetal doctors, neonatologists, anesthesiologists and infective disease specialists. $^{[20]}$

\section{Breastfeeding}

The risk of transmission during breastfeeding is largely unknown. Very few reported cases provided information on the risk of newborn infection during breastfeeding. Preliminary data suggest that the virus is not detectable in milk, ${ }^{[6]}$ but different vision remain about breastfeeding and mother-baby contact after delivery.

Elements to consider include clinical conditions of the mother and child, test result of the mother (confirmed or suspected) and mother's desire to breastfeed. Not least, the negative effects of the separation between mother and child should also be considered. ${ }^{[2]]}$

A mother with suspected, probable, or confirmed COVID-19 should be counseled to take all possible precautions to avoid spreading the virus to her infant, such as wearing a mask and washing her hands.

Moreover, symptomatic mothers who must be separated from their newborns might use pumps to express breast milk. ${ }^{[12]}$

\section{Management and Therapy}

In the absence of obstetric problems, pregnant women with COVID-19 infection and mild disease do not require hospital treatment and they should perform self-isolation at home, similarly to non-pregnant patients. Conversely, pregnant patients with suspected or confirmed COVID-19 infection and more severe symptoms or obstetrical complications need hospital care. $^{[20]}$

Compared to nonpregnant women, in pregnancy there are some additional issues to consider, such as 
fetal monitoring and the maintenance of a good maternal oxygenation level, that COVID-19 infection can compromise, to warrant fetal well-being. ${ }^{[20]}$

In view of the potential higher risk of thrombotic adverse events, pregnant and postpartum women with COVID-19 admitted to the hospital are frequently treated with low molecular weight heparin (LMWH) for thromboembolism prophylaxis. ${ }^{[20]}$

Both hydroxychloroquine and chloroquine have been reported to inhibit SARS-CoV-2 in vitro, but their role in treatment of COVID-19 is under investigation. ${ }^{[2]}$ Data from early randomized trials are mixed and do not suggest a clear benefit. Hydroxychloroquine crosses the placenta. Accumulation in fetal ocular tissues has been observed in animal studies, but fetal ocular toxicity has not been observed in humans, which is reassuring given that the drug has been widely used by pregnant women for treatment of systemic lupus erythematosus or for malaria. ${ }^{[2]}$

Regarding antiviral drug therapy several agents are being evaluated for treatment of COVID-19, such as Kaletra (Lopinavir/Ritonavir), Darunavir/Cobicistat, Arbidol (Umifenovir), Remdesivir, or Favipiravir (22). Although some of these agents are clinically available for other indications their use for COVID-19 is still a subject of debate.

Remdesivir is a novel nucleotide analogue that has activity against SARS-CoV-2 in vitro ${ }^{[2]}$ and related coronaviruses included SARS and MERS both in vitro and in animal studies. ${ }^{[23]}$

A double-blind, randomized, placebo-controlled trial of intravenous Remdesivir in adults hospitalized with COVID-19 with evidence of lower respiratory tract involvement showed that Remdesivir was superior to placebo in shortening the time to recovery. ${ }^{[2]}$

In the WAPM study ${ }^{[16]}$ pharmacological treatment with LMWH and antiviral drugs was associated with a significantly lower rate of composite maternal outcome, while no difference was found among different therapies when assessing adverse composite perinatal outcomes. In this scenario, the authors conclude that in the absence of proven therapy, currently the care of patients with SARS-CoV-2 should be mostly based on supportive care, and further evidence is needed before drawing any robust conclusion.

\section{Psychological Impact of COVID-19 in Pregnant Women}

The COVID-19 outbreak poses significant risk to public health, including mental health. During pregnancy, women experience elevated levels of stress and anxiety associated with potential adverse obstetrical outcomes such as intrauterine fetal death or fetal abnormalities. Stress and anxiety may also increase during infectious disease outbreaks. A recent cross-sectional survey study aimed to evaluate psychological impact and anxiety in pregnant women during the COVID-19 outbreak in Italy using validated questionnaires. ${ }^{[2]}$ The study showed that the COVID-19 outbreak had a moderateto-severe phycological impact on pregnant women. More than two third of the women also reported anxiety higher than the normal. Almost half of the women $(46 \%)$ reported high anxiety regarding the vertical transmission of the disease.

\section{Ethical Perspective}

The COVID-19 epidemic is necessitating a global bioethics reflection and response. A bioethics and ethics of science and technology perspective, rooted in human rights, should play a key role in the context of this challenging pandemic. On both national and international levels, health and social policies should be based on solid evidence, taking into account the uncertainties that exist during epidemic, especially in case of a novel pathogen. Epidemics clearly expose the strength and weaknesses of the healthcare systems in different countries, as well as the obstacles and inequities of access to healthcare. In summary, from an ethical point of view, there is an urgent need for coordination of international efforts and the formulation of common understanding of ethical review processes. ${ }^{[25]}$

\section{Conclusion}

The lack of data during the first and early second trimester does not allow to ascertain whether a seroconversion during early pregnancy may increase the risk of adverse perinatal outcomes and how it should be treated and monitored once the infection has passed. Another peculiar issue is whether infection before term is associated with a higher severity of pulmonary disease, due to the progressive lung adaptation occurring in the first trimester. However, at the moment there is 
no univocal indication for the initiation of intensive maternal surveillance and no defined criteria to identify pregnant women who need mechanical ventilation. Importantly, there is no reported evidence on the type and frequency of fetal monitoring in critically-ill women and if increasing fetal surveillance may reduce fetal morbidities. Future studies should aim at reporting the actual risk of severe disease when infection is contracted in early pregnancy, the most appropriate type and frequency of fetal monitoring and the optimal timing of delivery.

Conflicts of Interest: No conflicts declared.

\section{References}

1. Johns Hopkins University. COVID-19 dashboard by the Center for Systems Science and Engineering (CSSE) at Johns Hopkins University (JHU). [Internet]. Baltimore, MD: Johns Hopkins University. [updated 2020 May 27; cited 2020 May 27]. Available from: https://coronavirus.jhu.edu/map.html

2. Chan JF-W, Kok K-H, Zhu Z, Chu H, To KK-W, Yuan S, et al. Genomic characterization of the 2019 novel human-pathogenic coronavirus isolated from a patient with atypical pneumonia after visiting Wuhan. Emerg Microbes Infect 2020;9:221-36. [PubMed] [CrossRef]

3. WHO. World Health Organization guidelines for the global surveillance of severe acute respiratory syndrome (SARS). [Internet]. Geneva: World Health Organization. [updated 2004 Oct; cited 2020 May 27]. Available from: https://www. who.int/csr/resources/publications/WHO_CDS_CSR_ARO_ 2004_1.pdf?ua=1

4. WHO Regional Office for Eastern Mediterranean. MERS situation update. [Internet]. Geneva: World Health Organization. [updated 2020 Jan; cited 2020 Mar 15]. Available from: http:// www.emro.who.int/pandemic-epidemic-diseases/mers-cov/ mers-situation-update-january-2020.html

5. Wang DW, Hu B, Hu C, Zhu F, Liu X, Zhang J, et al. Clinical characteristics of 138 hospitalized patients with 2019 novel coronavirus-infected pneumonia in Wuhan, China. JAMA 2020;7;323:1061-9. [PubMed] [CrossRef]

6. WHO. Clinical management of severe acute respiratory infection (SARI) when COVID-19 disease is suspected. Interim guidance. [Internet]. Geneva: World Health Organization. [updated 2020 Mar 13; cited 2020 Mar 13]. Available from: https://apps.who.int/iris/handle/10665/331446

7. WHO. Coronavirus disease (COVID-19) technical guidance: laboratory testing for 2019-nCoV in humans. [Internet]. Geneva: World Health Organization. [updated 2020 May 13; cited 2020 May 13]. Available from: https://www.who.int/emergencies/diseases/novel-coronavirus2019/technical-guidance/ laboratory-guidance
8. Zhao J, Yuan Q, Wang H, Liu W, Liao X, Su Y, et al. Antibody responses to SARS-CoV-2 in patients of novel coronavirus disease 2019. Clin Infect Dis 2020 Mar 28. pii: ciaa344. [PubMed] [CrossRef]

9. Jin Y, Wang M, Zuo Z, Fan C, Ye F, Cai Z, et al. Diagnostic value and dynamic variance of serum antibody in coronavirus disease 2019. Int J Infect Dis 2020;94:49-52. [PubMed] [CrossRef]

10. Li Z, Yi Y, Luo X, Xiong N, Liu Y, Li S, et al. Development and clinical application of a rapid IgM-IgG combined antibody test for SARS-CoV-2 infection diagnosis. J Med Virol 2020 Feb 27; doi: 10.1002/jmv.25727 [PubMed] [CrossRef]

11. Chen H, Guo J, Wang C, Luo F, Yu X, Zhang W, et al. Clinical characteristics and intrauterine vertical transmission potential of COVID-19 infection in nine pregnant women: a retrospective review of medical records. Lancet 2020;395:809_ 15. [PubMed] [CrossRef]

12. Jamieson D, Honein MA, Rasmussen SA, Williams JL, Swerdlow DL, Biggerstaff MS, et al.; Novel Influenza A (H1N1) Pregnancy Working Group. H1N1 2009 influenza virus infection during pregnancy in the USA. Lancet 2009;374: 451-8. [PubMed] [CrossRef]

13. COVID-19 Treatment Guidelines Panel. Coronavirus disease 2019 (COVID-19) treatment guidelines. [nternet]. Baltimore, MD: National Institutes of Health. [updated 2020 May 12; cited 2020 May 13]. Available from: https://www.covid19treatmentguidelines.nih.gov/

14. Wu Z, McGoogan JM. Characteristics of and important lessons from the coronavirus disease 2019 (COVID-19) outbreak in China: summary of a report of 72,314 cases from the Chinese Center for Disease Control and Prevention. JAMA 2020;323: 1239-42. [PubMed] [CrossRef]

15. Guan WJ, Ni ZY, Hu Y, Liang WH, Ou CQ, He JX, et al.; China Medical Treatment Expert Group for Covid-19. Clinical characteristics of coronavirus disease 2019 in China. N Engl J Med 2020;382:1708-20. [PubMed] [CrossRef]

16. Saccone G, Sen C, Di Mascio D, Galindo A, Grünebaum A, Yoshimatsu J, et al. WAPM (World Association of Perinatal Medicine) working group on COVID-19. Maternal and perinatal outcomes of pregnant women with Coronavirus Disease 2019 (COVID-19): The WAPM study on COVID-19. 2020, Lancet, under review.

17. Di Mascio D, Khalil A, Saccone G, Rizzo G, Buca D, Liberati $\mathrm{M}$, et al. Outcome of Coronavirus spectrum infections (SARS, MERS, COVID 1-19) during pregnancy: a systematic review and meta-analysis. Am J Obstet Gynecol MFM 2020;2:100107. [PubMed] [CrossRef]

18. Silasi M, Cardenas I, Kwon JY, Racicot K, Aldo P, Mor G. Viral infections during pregnancy. Am J Reprod Immunol 2015;73:199-213. [PubMed] [CrossRef]

19. Zeng L, Xia S, Yuan W, Yan K, Xiao F, Shao J, et al. Neonatal early-onset infection with SARS-CoV-2 in 33 neonates born to mothers with COVID-19 in Wuhan, China. JAMA Pediatr 2020;26:e200878. [PubMed] [CrossRef] 
20. Boelig RC, Manuck T, Oliver EA, Di Mascio D, Saccone, G, Bellussi F, et al. Labor and delivery guidance for COVID-19. Am J Obstet Gynecol MFM 2020;2:100110. [PubMed] [CrossRef]

21. Stuebe, A. Should infants be separated from mothers with COVID-19? First, do no harm. Breastfeed 2020;15:351-2. [PubMed] [CrossRef]

22. Wang M, Cao R, Zhang L, Yang X, Liu J, Xu M, et al. Remdesivir and chloroquine effectively inhibit the recently emerged novel coronavirus $(2019-\mathrm{nCoV})$ in vitro. Cell Res 2020;30:269-71. [PubMed] [CrossRef]
23. Sheahan TP, Sims AC, Graham RL, Menachery VD, Gralinski LE, Case JB, et al. Broad-spectrum antiviral GS5734 inhibits both epidemic and zoonotic coronaviruses. Sci Transl Med 2017;9(396):eaal3653. [PubMed] [CrossRef]

24. Saccone G, Florio A, Aiello F, Venturella R, De Angelis MC, Locci $M$, et al. Psychological impact of coronavirus disease 2019 in pregnant women. Am J Obstet Gynecol 2020;S00029378(20)30527-5. [PubMed] [CrossRef]

25. International Bioethics Committee (IBC). Statement on COVID-19: ethical considerations from a global perspective. [Internet]. Paris: UNESCO. [cited 2020]. Available from: https://unesdoc.unesco.org/ark:/48223/pf0000373115

Bu makalenin kullanım izni Creative Commons Attribution-NoCommercial-NoDerivs 3.0 Unported (CC BY-NC-ND3.0) lisansı aracılığılyla bedelsiz sunulmaktadır. / This work is licensed under the Creative Commons Attribution-NonCommercial-NoDerivs 3.0 Unported (CC BY-NC-ND3.0) License. To view a copy of this license, visit http://creativecommons.org/licenses/by-nc-nd/3.0/ or send a letter to Creative Commons, PO Box 1866, Mountain View, CA 94042, USA. 